\title{
Fetal biometry assessment with Intergrowth 21st's and Salomon's equations in rural Burkina Faso
}

Biébo Bihoun ${ }^{1,2^{*}}$, Serge Henri Zango ${ }^{1,2}$, Maminata Traoré-Coulibaly ${ }^{1}$, Innocent Valea ${ }^{1}$, Raffaella Ravinetto ${ }^{3}$, Jean-Pierre Van Geertruyden ${ }^{4}$, Umberto D'Alessandro ${ }^{5}$, Halidou Tinto ${ }^{1}$ and Annie Robert ${ }^{2}$

\begin{abstract}
Background: Ultrasound scanning during the 2nd or the 3rd trimester of pregnancy for fetal size disturbances screening is heavily dependent of the choice of the reference chart. This study aimed to assess the agreement of Salomon and the Intergrowth 21 st equations in evaluating fetal biometric measurements in a rural area of Burkina Faso, and to measure the effect of changing a reference chart.
\end{abstract}

Methods: Data collected in Nazoanga, Burkina Faso, between October 2010 and October 2012, during a clinical trial evaluating the safety and efficacy of several antimalarial treatments in pregnant women were analyzed. We included singleton pregnancies at 16-36 weeks gestation as determined by ultrasound measurements of fetal bi-parietal diameter (BPD), head circumference (HC), abdominal circumference (AC) and femur length (FL). Expected mean and standard deviation at a given gestational age was computed using equations from Salomon references and using Intergrowth 21st standard. Then, z-scores were calculated and used subsequently to compare Salomon references with Intergrowth 21st standards.

Results: The analysis included 276 singleton pregnancies.

Agreement was poor except for HC: mean difference -0.01 , limits of agreement -0.60 and 0.59 . When AC was used as a surrogate of fetal size, switching from the reference of Salomon to the standards of Intergrowth 21st increased ten times the proportion of fetuses above the 90th percentile: 2.9 and $31.2 \%$, respectively.

Mean differences were larger in the third trimester than in the second trimester. However, agreement remained good for $\mathrm{HC}$ in both trimesters.

Difference in the proportion of AC measurements above the 90th percentile using Salomon and Intergrowth 21st equations was greater in the second trimester (2.6 and 36.3\%, respectively) than in the third trimester (3.5 and 19.8\%, respectively). The greatest difference between the two charts was observed in the number of FL measurements classified as large in the second trimester (6.8 and 54.2\%, using Salomon and Intergrowth 21st equations, respectively).

Conclusion: The agreement between Intergrowth 21st and Salomon equations is poor apart from HC. This would imply different clinical decision regarding the management of the pregnancy.

Keywords: Biometry, References, Standards, Burkina Faso

\footnotetext{
* Correspondence: biebo.bihoun@uclouvain.be; behoonj@yahoo.fr

${ }^{1}$ IRSS-Clinical Research Unit of Nanoro, Nanoro, Burkina Faso

${ }^{2}$ Intitut de recherche expérimentale et clinique, Université catholique de Louvain, Brussels, Belgium

Full list of author information is available at the end of the article
}

C The Author(s). 2020 Open Access This article is licensed under a Creative Commons Attribution 4.0 International License, which permits use, sharing, adaptation, distribution and reproduction in any medium or format, as long as you give appropriate credit to the original author(s) and the source, provide a link to the Creative Commons licence, and indicate if changes were made. The images or other third party material in this article are included in the article's Creative Commons licence, unless indicated otherwise in a credit line to the material. If material is not included in the article's Creative Commons licence and your intended use is not permitted by statutory regulation or exceeds the permitted use, you will need to obtain permission directly from the copyright holder. To view a copy of this licence, visit http://creativecommons.org/licenses/by/4.0/. The Creative Commons Public Domain Dedication waiver (http://creativecommons.org/publicdomain/zero/1.0/) applies to the data made available in this article, unless otherwise stated in a credit line to the data. 


\section{Background}

Ultrasound scanning during the 2nd or 3rd trimester of pregnancy allows fetal anthropometrics measurement [1] and screening for fetal size disturbances by comparison to reference values [2, 3].

Biparietal diameter (BPD), head circumference (HC), abdominal circumference (AC), and femur length (FL) are the most commonly measured parameters $[4,5]$.

Abnormal fetal biometric measurements could reflect underlying health issues like microcephalia, aneuploidy, genetic syndrome of skeletal dysplasia [6].

Early detection of abnormal fetal size helps obstetrician initiating further monitoring, planning and managing delivery in terms of labor induction or caesarian section $[6,7]$.

However, abnormal fetal size identification depends heavily on the choice of reference values. There is more than eighty references charts in the world [4]. A switching from one reference chart to another could raise tenfold the likeliness of identifying abnormal biometric measurements [8]. This could lead to expensive and stressful monitoring with additional investigations $[8,9]$. Also, fetal size depends of ethnicity and use of inadequate reference may result in harmful medical decisions $[10,11]$. For example, there is a risk of fetal loss in cases in which karyotype is demanded because of the invasive sampling method used [8]. Screening for fetal size disturbances using inappropriate reference chart may affect research conclusions and health policies as well $[8,10]$. Thus some authors recommended to use local reference for screening in a specific population [11-14]. In highincome countries, $[4,5]$ local biometric reference charts were adopted. Clear guidelines and recommendations for screening of abnormal fetal size and subsequent management were also put in place $[5,15-21]$. In low- and middle-income countries (LMICs), and particularly in sub-Saharan Africa, local charts are either lacking or not implemented where available [22-25]. The latter mostly refer to European charts [26], or charts preprogramed by default in the ultrasound device software [11-14, 27].

In 2014, the international fetal and newborn growth consortium for the twenty-first century (Intergrowth 21st) published fetal biometric standard equations based on selected healthy pregnancies from eight countries $[10,27]$. The aim was to provide charts that could be used anywhere in the world and to solve the issue of inadequate references [27]. Settings where local reference charts are lacking or not implemented are likely to replace the charts they are currently using by this new chart. However, knowing the variation between nomograms in assessing fetal size and the clinical implication, it would be cautious to check whether adaptation is needed before adopting or replacing a chart in a specific population [14].
In Burkina Faso, no locally-adapted fetal biometry charts have been adopted or recommended in obstetric ultrasound practice. Rather, French references or other European references set by default in the ultrasound machines are used. Indeed in France, Salomon equations were recommended until 2018 [28].

Both the Salomon and Intergrowth 21st equations allow the calculation of a mean and a standard deviation by gestational age and the computation of a standardized $z$-score for the individual fetus. The objective of the present analysis was to assess the difference between $\mathrm{z}$-scores derived from Salomon and from Intergrowth 21st equations using fetal biometric measurements in pregnant women from rural areas of Burkina Faso, and to measure the effect of changing a reference chart.

\section{Methods}

\section{Study settings and population}

The current dataset is from the trial "Safe and efficacious artemisinin-based combination treatment for African pregnant women with malaria" (PREGACT) conducted from June 2010 to August 2013 [NCT00852423 (ClinicalTrials.gov)]. The primary study evaluated the efficacy and safety of four artemisinin-based combinations treatment in women with malaria in the 2nd and 3rd trimester of pregnancy. The trial was implemented in four countries, namely Burkina Faso, Ghana, Malawi, and Zambia. Methods and results have been already published $[29,30]$. This analysis used data collected in Nazoanga, Burkina Faso, where fetal biometric measurements at inclusion by ultrasound were carried out, to exclude women in the 1st trimester.

\section{Ultrasound}

This study was cross-sectional. Ultrasonographic examination of the pregnant women was performed once at inclusion. However, three participants had their scan repeated a second time at screening to confirm gestational age as per the quality assurance system put in place [31,

Table 1 General characteristics of the mothers

\begin{tabular}{ll}
\hline Age (years) & $23(20 ; 29)$ \\
Gravidity & $3(1 ; 4)$ \\
Parity & $2(0 ; 3)$ \\
Weight $(\mathrm{kg})$ & $54 \pm 6$ \\
Height $(\mathrm{cm})$ & $162 \pm 7$ \\
Body mass index $\left(\mathrm{kg} / \mathrm{m}^{2}\right)$ & $20.5 \pm 1.7$ \\
Symphysis-fundal height $(\mathrm{cm})$ & $24(21 ; 28)$ \\
Gestational age (weeks) & $25(21 ; 29)$ \\
Hemoglobin $(\mathrm{g} / \mathrm{dL})$ & $10.1 \pm 1.2$ \\
\hline
\end{tabular}

Numbers are mean \pm standard deviation or median (IQR) IQR interquartile range 
32]. A Fukuda Denshi@ portable ultrasound scanner FFsonic UF- 4100 with a $3.5 \mathrm{MHz}$ or $5.0 \mathrm{MHz}$ probes was used for transabdominal examination according to woman's thinness.

Four biometric parameters were measured. BPD and $\mathrm{HC}$ were both obtained in a transverse view of the fetal head with the following landmarks: midline echo corresponding to the fax cerebri, its anterior third interrupted by the cavum septi pellucidi, symmetry of thalami at each side. BPD was measured from the inner to the outer wall of the skull. HC measurement was realized by placing an ellipse around the outer border of the skull. $\mathrm{AC}$ was measured by applying the ellipse on the external border of the abdomen in a cross-sectional plane showing the stomach bulbe and the anterior third of the umbilical vein. FL measurement was obtained in a plane where the femoral diaphysis was fully visible, with calipers placed on the both ends. All measurements were done according to specific standard operating procedures [31, 32]. Gestational age in complete weeks was automatically derived from the four anthropometric measurements according to Hadlock formula [32, 33]

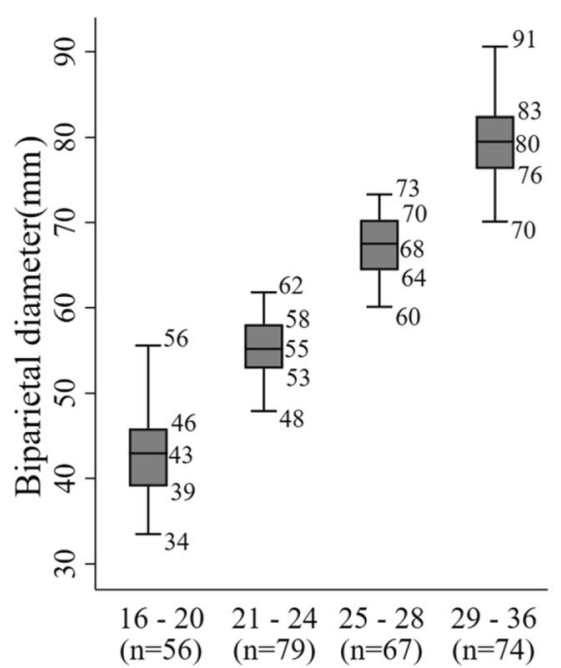

A

Gestational age (weeks)

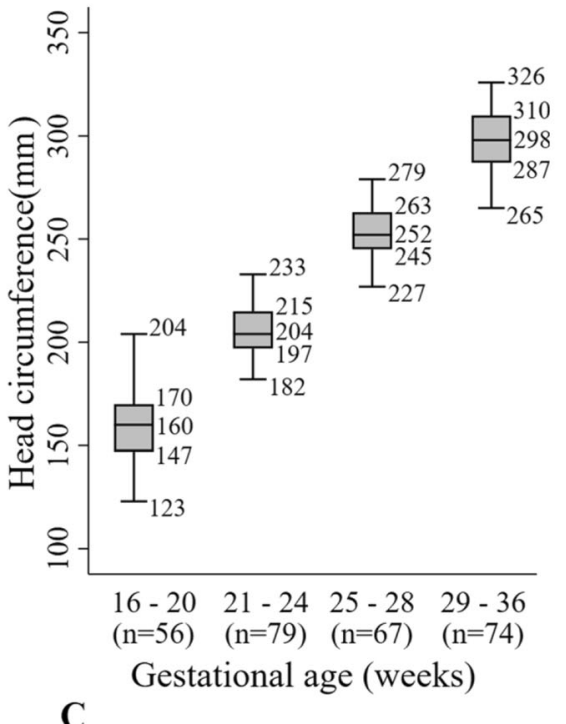

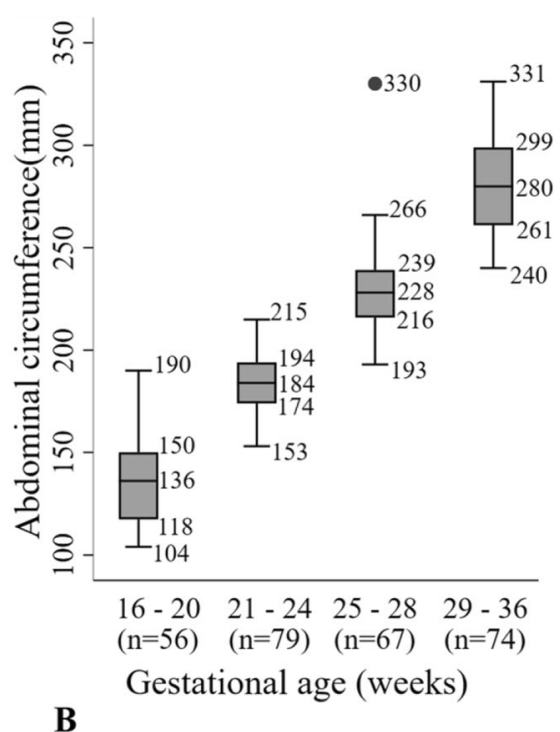

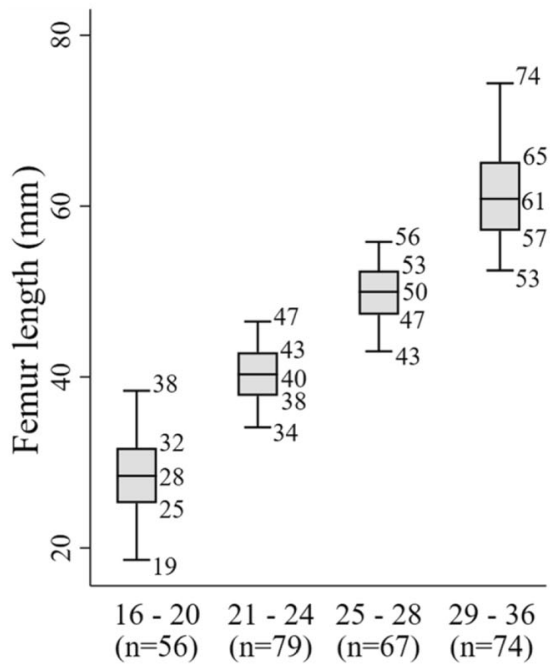

D

Fig. 1 Fetal biometry measurements by gestational age. a: Biparietal diameter. b: Abdominal circumference. c: Head circumference. d: Femur length. Intergrowth 21: International fetal and newborn growth consortium for the twenty-first century. The numbers at the right of the boxplots represented from the bottom to the top: the minimum without outliers, the first quartile, the median, the third quartile and the maximum without outliers 


\section{Statistical analysis}

Three participants have their scan repeated once at screening to confirm gestational age as per the quality assurance system $[29,30]$. We took this into account by averaging the two measurements for each biometric parameter.
The expected mean and expected standard deviation for $\mathrm{BPD}, \mathrm{HC}, \mathrm{AC}$ and $\mathrm{FL}$ for the gestational age were computed for each fetus using equations from Salomon [16] and Intergrowth 21st [27]. The z-scores [(Observed value - Expected mean)/Expected SD] of the two equations were compared. Square-diagonal scatter plots were

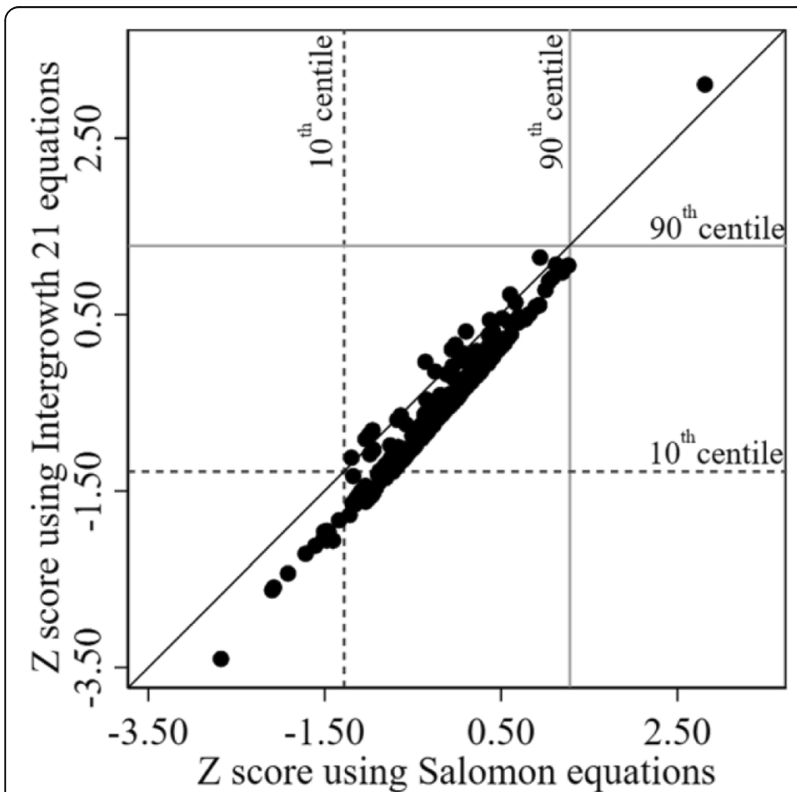

A

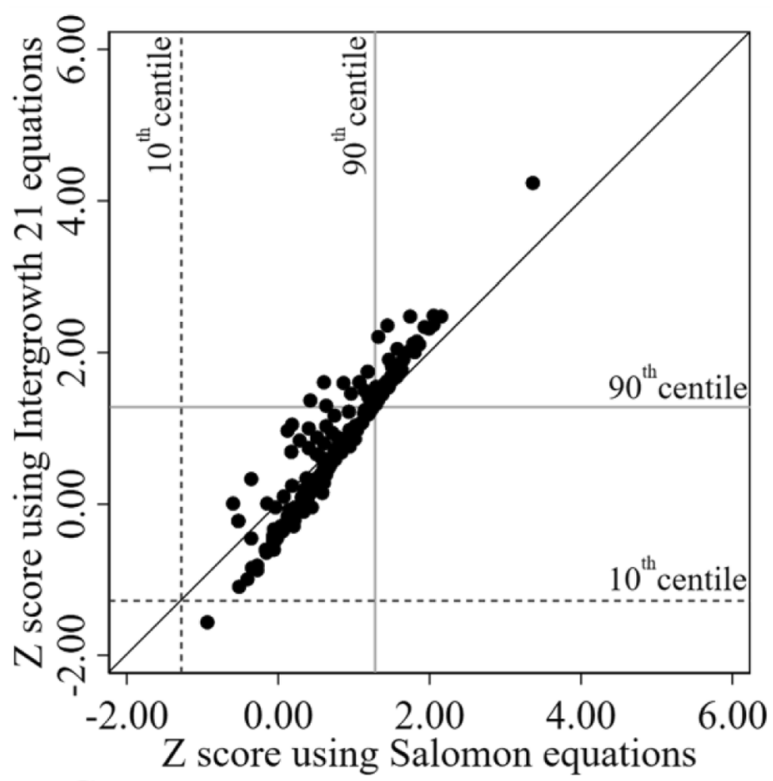

C

Fig. 2 Number of standard deviations from the mean using Salomon or Intergrowth 21 eqs. a: Biparietal diameter. b: Abdominal circumference. c: Head circumference. d: Femur length. Intergrowth 21: International fetal and newborn growth consortium for the twenty-first century. Dashed horizontal and vertical grey lines referred to a $z$ score of -1.282 corresponding to the 10th centile. Solid horizontal and vertical grey lines referred to a $z$ score of 1.282 corresponding to the 90 th centile. The black oblique line is the perfect concordance line where the $z$-scores from Intergrowth 21 st and Salomon equations are equal
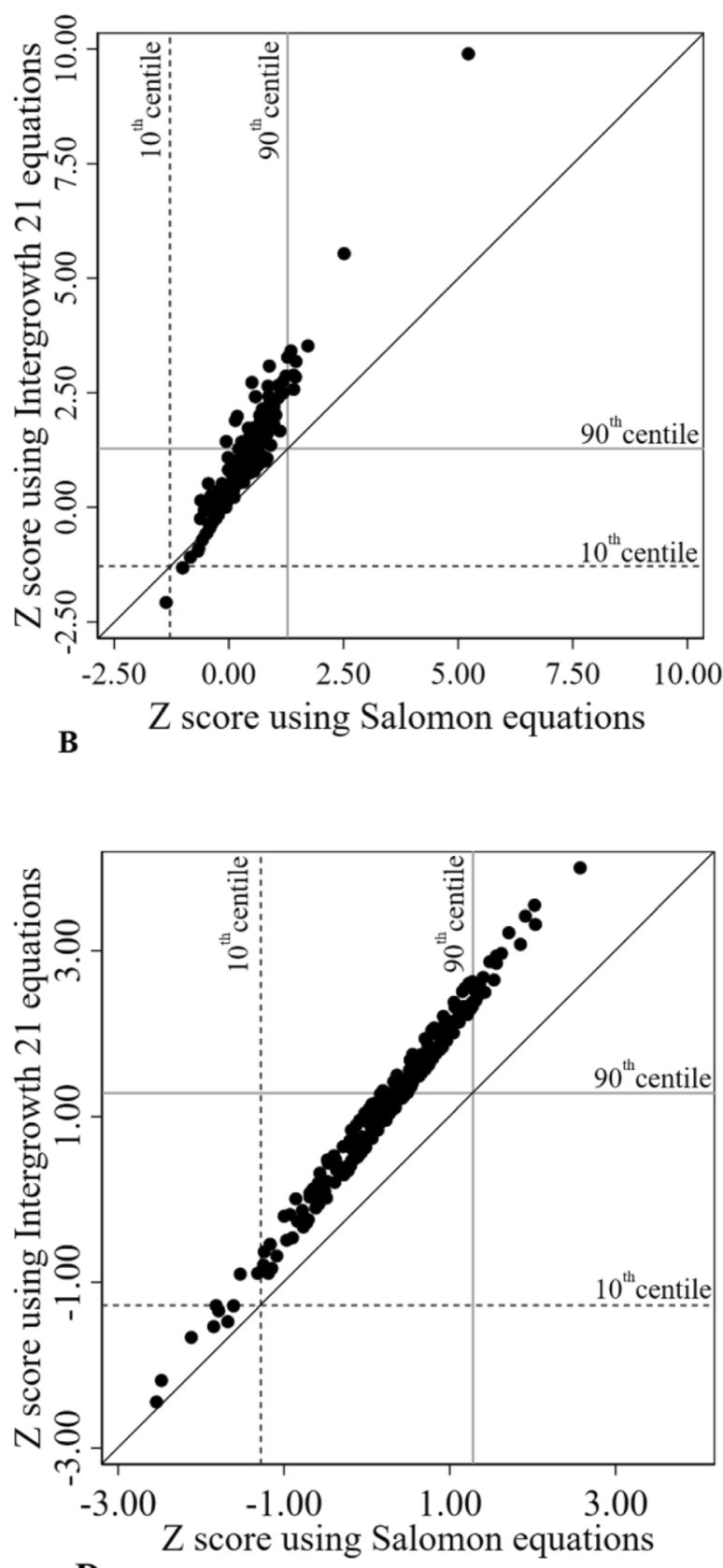

D 
drawn to allow visual evaluation of the relationship between the two sets of z-scores. All differences (Intergrowth 21st z-score - Salomon z-score) were compared using paired $\mathrm{t}$ test and Wilcoxon signed ranks test. A $p$ value $<0.05$ was considered as statistically significant. Linear relationship was checked by performing linear regression of Intergrowth 21st z-scores by Salomon zscores.

Level of agreement between the charts was checked using Bland-Altman analysis. Individual scores averages were plotted horizontally against their differences vertically. Limits of agreement (LOA) were obtained by applying the following formula: mean of differences \pm 1.96 standard deviation.

A mean difference of zero and limits of agreement within -0.50 and 0.50 were considered as a good agreement [34].

Reliability between the two charts was expressed by the intraclass correlation coefficient (ICC), calculated from a random effect one-way analysis of variance. Reliability was considered as weak, good or excellent if ICC values were $<0.40$, between 0.40 and 0.75 , or $>0.75$, respectively.

Abnormal measurement referred to either smallness ( $\mathrm{z}$ score $<-2.00$ corresponding to the 2.5 th centile, $\mathrm{z}$ score $<-1.282$ corresponding to the 10th centile) or largeness $(\mathrm{z}$-score $>1.282$ corresponding to the 90th centile, or $z$-score $>2.00$ corresponding to the 97.5th centile).

The effect of replacing one chart with another was measured using $\mathrm{AC}$ as a surrogate of fetal weight $[2,9]$.

STATA $^{\circ}$ statistical software version 15.1 StataCorp LLC, Texas, USA, was used for all analyses.

Ethics

Ethical approvals were obtained for the PREGACT study from the ethics committee of the University of Antwerp, Belgium, the institutional ethics committee of the Centre Muraz and the ethics committee of the Ministry of Health, Burkina Faso. Study participants or their legally authorized representative (for minors/not emancipated) signed (or thumb printed if illiterate) an informed consent form, before entering the study $[29,30]$. The data were anonymized.

\section{Results}

Out of the 285 pregnant women recruited in Nazoanga, 9 were excluded: 6 because of consent withdrawal and 3 because of twin pregnancy. Therefore, 276 participants were included in the current analysis. Recruited women were young (median age: 23 years), had several

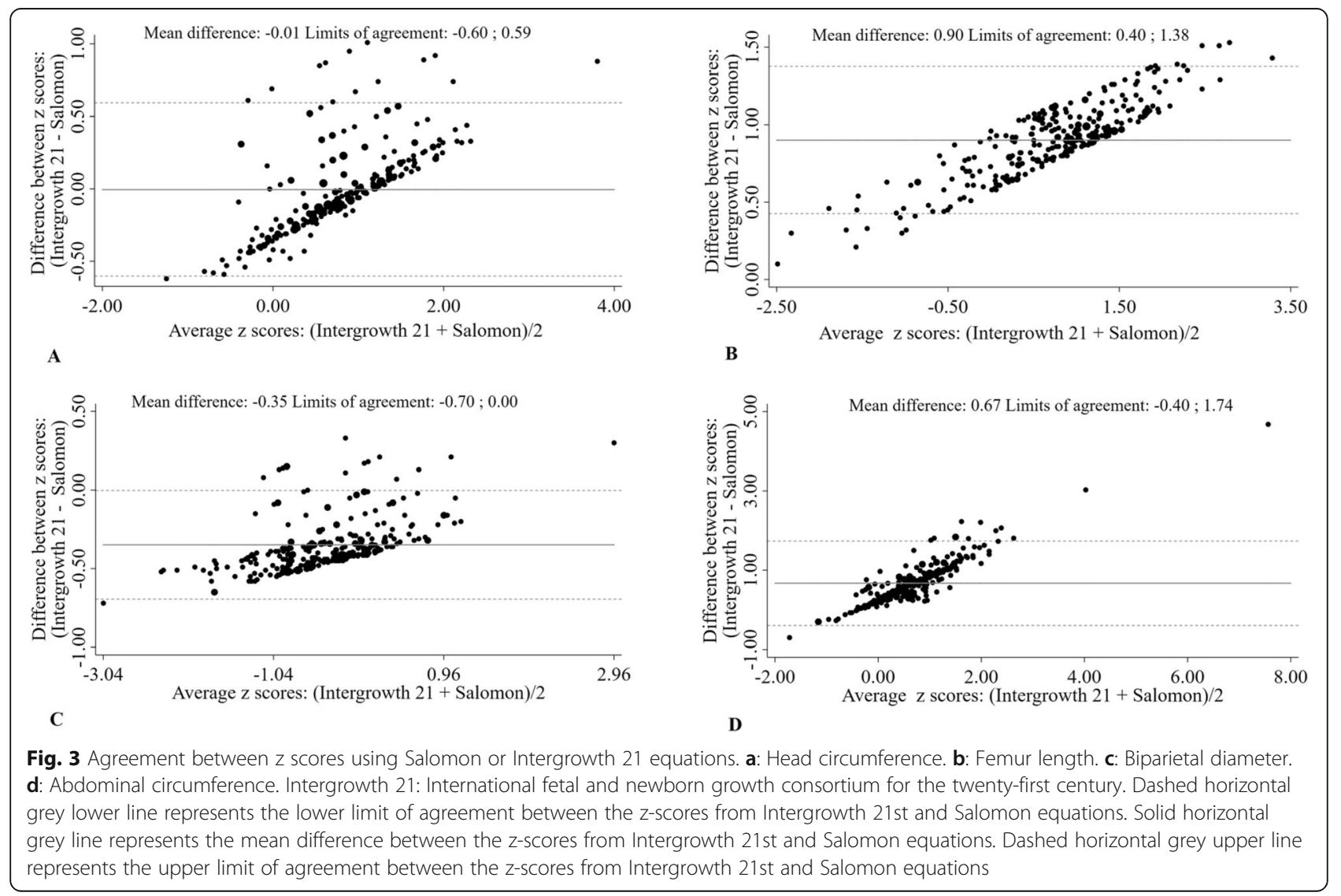


pregnancies (median gravidity: 3 ), and at inclusion had a median gestational age of 25 weeks (Table 1 ).

Median and interquartile range (IQR) of the measured parameters increased with increasing gestational age (Fig. 1).

Visual comparison by scatter plots of Intergrowth 21st 's to Salomon's z scores showed that they were underestimated in the low values of BPD (Fig. 2a), AC (Fig. 2b), and $\mathrm{HC}$ (Fig. 2c), and overestimated in the high values of AC (Fig. 2b), and HC (Fig. 2c); all z scores of FL were overestimated (Fig. 2d).

The two sets of $\mathrm{z}$ scores agreed poorly except for HC. The mean difference $(-0.01)$ was closed to zero and the limits of agreement ( -0.60 and 0.59$)$ were closed to the prespecified values of -0.5 and 0.5 . (Fig. 3a). Reliability ranged from good to excellent (see Additional file 1, Supplemental Table 1).

There was a strong linear correlation between the $\mathrm{z}$ scores by Intergrowth 21st equations and the $\mathrm{z}$ scores by Salomon equations. The slopes of linear regression of $\mathrm{z}$ scores using Intergrowth 21st equations over the $\mathrm{z}$ scores using Salomon equations ranged from 1.11 for BPD to 1.78 for AC (Fig. 4).

The percentages of fetal anthropometrics classified either as small or large are reported in Table 2. Globally, the number of measurements considered as large was greater than that of measurements considered as small, except for BPD. Also, percentages of fetuses with abnormal $\mathrm{z}$ scores by Intergrowth 21st equations were higher than those by Salomon equations. The effect of replacing Salomon reference by Intergrowth 21st standards was shown using AC as surrogate of fetal size. Large fetuses (above the 90th percentile) proportion using Salomon eqs. $(2.9 \%)$ was decupled when Intergrowth 21st equations were used (31.2\%).

In the second trimester, the agreement between $\mathrm{HC} \mathrm{z}$ scores using Intergrowth 21st equations and $\mathrm{z}$ scores using Salomon equations remained good: mean difference 0.03; limits of agreement -0.62 and 0.68 (Table 3). The proportions of large fetuses based on AC measurements above the 90th percentile were $36.3 \%$ by

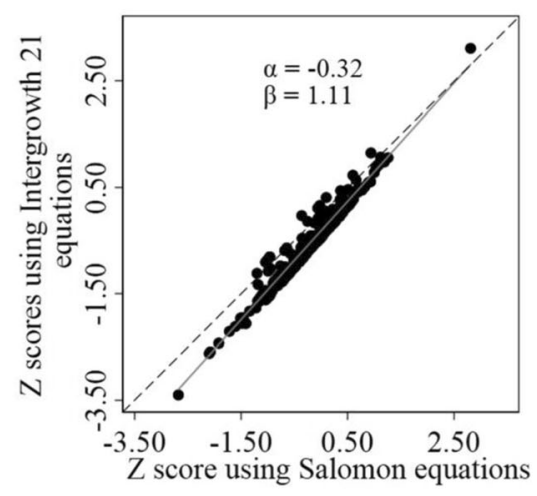

$\mathbf{A}$

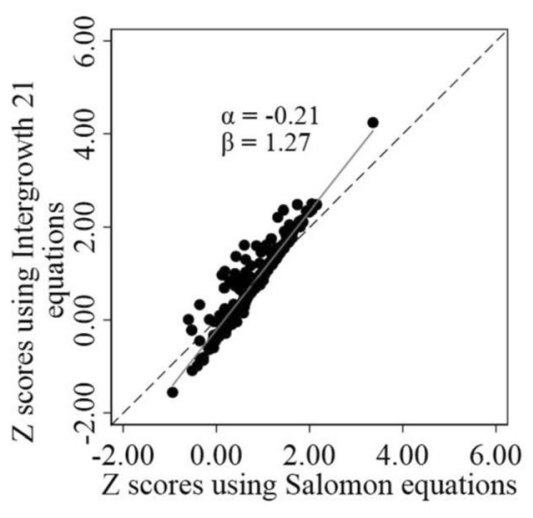

C

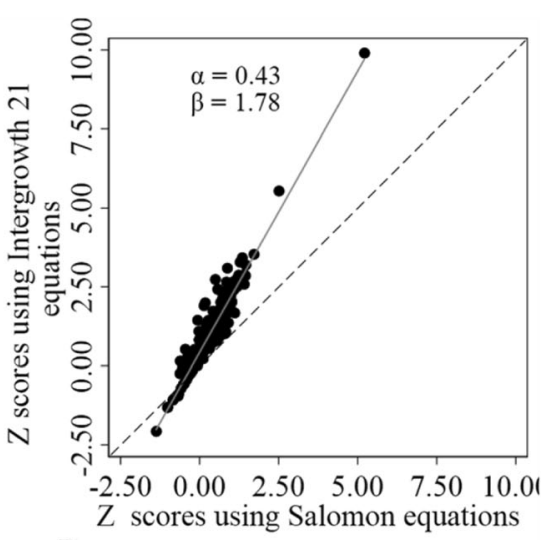

B

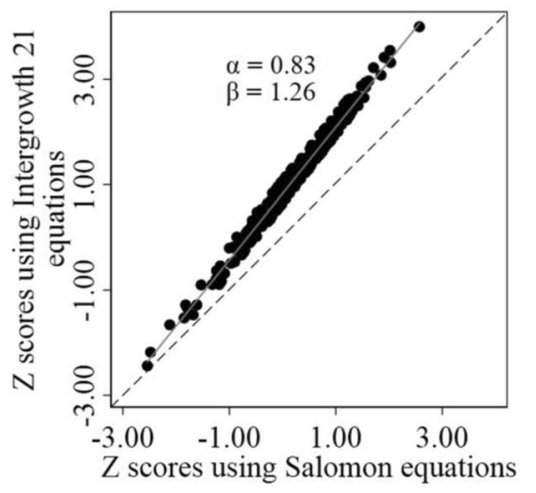

D

Fig. 4 Regression of Intergrowth 21 z-scores with Salomon z-scores. a: Biparietal diameter. b: Abdominal circumference. c: Head circumference. d: Femur length. Intergrowth 21: International fetal and newborn growth consortium for the twenty-first century. Dashed oblique black line represents the perfect agreement between the z-scores from Intergrowth 21st and Salomon equations. Solid oblique grey line represents the linear regression fitted line 
Table 2 Fetuses with abnormal z scores using Intergrowth 21st or Salomon equations

\begin{tabular}{|c|c|c|c|c|}
\hline \multirow[t]{2}{*}{ Anthropometrics } & \multicolumn{4}{|c|}{ Abnormal z score n (\%) } \\
\hline & $<2.5$ th centile & $<10$ th centile & $>$ 90th centile & $>97.5$ th centile \\
\hline \multicolumn{5}{|l|}{ Biparietal diameter } \\
\hline Intergrowth 21 & $10(3.6)$ & $39(14.1)$ & $1(0.4)$ & $1(0.4)$ \\
\hline Salomon & $3(1.1)$ & $14(5.1)$ & $1(0.4)$ & $1(0.4)$ \\
\hline Mc Nemar test & n.a & $<0.001$ & n.a & n.a \\
\hline \multicolumn{5}{|c|}{ Abdominal circumference } \\
\hline Intergrowth 21 & $1(0.4)$ & $3(1.1)$ & $86(31.2)$ & $33(12.0)$ \\
\hline Salomon & $0(0.0)$ & $1(0.4)$ & $8(2.9)$ & $2(0.7)$ \\
\hline Mc Nemar test & n.a & n.a & $<0.001$ & $<0.001$ \\
\hline \multicolumn{5}{|c|}{ Head circumference } \\
\hline Intergrowth 21 & $0(0.0)$ & $1(0.4)$ & $68(24.6)$ & $19(6.9)$ \\
\hline Salomon & $0(0.0)$ & $0(0.0)$ & $52(18.8)$ & $4(1.4)$ \\
\hline Mc Nemar test & n.a & n.a & $<0.001$ & $<0.001$ \\
\hline \multicolumn{5}{|l|}{ Femur length } \\
\hline Intergrowth 21 & $2(0.7)$ & $6(2.2)$ & $137(49.6)$ & $49(17.8)$ \\
\hline Salomon & $3(1.1)$ & $10(3.6)$ & $18(6.5)$ & $3(1.1)$ \\
\hline Mc Nemar test & n.a & n.a & $<0.001$ & $<0.001$ \\
\hline
\end{tabular}

n.a not applicable; Intergrowth 21: international fetal and newborn growth consortium for the twenty-first century

Intergrowth 21st equations and $2.6 \%$ by Salomon equations. However, the greatest difference in large biometric measurements between the four parameters was observed in FL (6.8\% and 54. 2\%, using Salomon and Intergrowth 21st equations respectively) (Table 4).

In the third trimester mean difference between $\mathrm{HC} \mathrm{z}$ scores was -0.09 and limits of agreement were -0.52 and 0.35 (Table 5). Large fetuses detected by $\mathrm{AC} \mathrm{z}$ scores above the 90th percentiles were 19.8 and 3.5\% using Intergrowth 21st and Salomon equations, respectively (Table 6).

\section{Discussion}

The aim of our study was to determine the differences between fetuses' size patterns estimated by Salomon references or Intergrowth 21st standards in a sub-Saharan African rural population, rather than estimating the actual status of smallness or largeness.

The differences between the means of $z$-scores of the four biometric parameters estimated by the two methods were all statistically significant. Intergrowth 21 st equations gave the greatest scores, particularly for FL. Therefore, the charts agreed poorly, except for HC.

These findings revealed differences between our population and the populations used for the charts $[1,10]$. Indeed, Salomon's chart was developed on the basis of a cohort of pregnant women followed up in France which probably is ethnically different from our cohort of Burkinabe pregnant women, [16] possibly explaining the observed discrepancies [12-14]. Nevertheless, the development of Intergrowth 21st equations included African pregnant women [27] but had greater means of $\mathrm{z}$-scores, meaning that other factors than ethnicity could explain the differences observed. Intergrowth 21st equations were derived on the basis of healthy, well-nourished women [10] and thus describe growth under optimal conditions $[1,10]$. References of Salomon imposed few constraints regarding adequacy of the nutritional or health status [16]. Our study population included malaria-infected pregnant women living in rural Burkina Faso [29]; on average observed measures were more distant from standards and closer to references, suggesting that ideal fetal growth conditions were not fulfilled. Nevertheless, the negative means of BPD z-scores were probably due to systematic variations in head measurement methods as already shown in another publication [34]. BPD was obtained by placing calipers in the center of the width of the skull bone, from outer-to-outer and from outer-to-inner margins, in the study of Salomon's, Intergrowth 21st study and in our study [16, 27, 32].

Despite these disparities, both charts agreed roughly on $\mathrm{HC}$ measurements. This finding reinforces the choice of $\mathrm{HC}$ as a single "non-fat marker" for comparison of fetal size across populations $[4,10]$.

It was recently shown that FL $\mathrm{z}$ scores between Intergrowth 21st and Salomon's equations were largely divergent in France, [34] a difference also observed in our study that may be due to the evolution in ultrasound technology [35]. Indeed, recent ultrasound equipment's such as those used in the Intergrowth 21st study have thinner beam and yield 
Table 3 Agreement and reliability of fetal biometrics z scores using Intergrowth 21st and Salomon equations in the second trimester

\begin{tabular}{|c|c|c|c|c|c|}
\hline Anthropometrics & Mean \pm SD & p-value & Median (IQR) & p-value ${ }^{\dagger}$ & Range \\
\hline \multicolumn{6}{|l|}{ Biparietal diameter } \\
\hline Intergrowth 21 & $-0.48 \pm 0.72$ & & $-0.47(-0.98 ;-0.04)$ & & $-3.40 ; 3.11$ \\
\hline Salomon & $-0.15 \pm 0.63$ & & $-0.12(-0.60 ; 0.24)$ & & $-2.68 ; 2.81$ \\
\hline Difference & $-0.33 \pm 0.21$ & $<0.001$ & $-0.40(-0.48 ;-0.22)$ & $<0.001$ & $-0.72 ; 0.33$ \\
\hline LOA & $-0.74 ; 0.07$ & & & & \\
\hline ICC & 0.85 & & & & \\
\hline \multicolumn{6}{|c|}{ Abdominal circumference } \\
\hline Intergrowth 21 & $1.05 \pm 1.18$ & & $0.95(0.35 ; 1.59)$ & & $-2.07 ; 9.90$ \\
\hline Salomon & $0.29 \pm 0.63$ & & $0.23(-0.03 ; 0.58)$ & & $-1.37 ; 5.22$ \\
\hline Difference & $0.77 \pm 0.60$ & $<0.001$ & $0.69(0.40 ; 1.01)$ & $<0.001$ & $-0.70 ; 4.68$ \\
\hline LOA & $-0.40 ; 1.94$ & & & & \\
\hline $\mathrm{ICC}^{\ddagger}$ & 0.54 & & & & \\
\hline \multicolumn{6}{|l|}{ Head circumference } \\
\hline Intergrowth 21 & $0.75 \pm 0.81$ & & $0.72(0.14 ; 1.29)$ & & $-1.56 ; 4.24$ \\
\hline Salomon & $0.72 \pm 0.61$ & & $0.67(0.31 ; 1.14)$ & & $-0.94 ; 3.36$ \\
\hline Difference & $0.03 \pm 0.33$ & 0.18 & $-0.02(-0.22 ; 0.23)$ & 0.85 & $-0.62 ; 1.01$ \\
\hline LOA & $-0.62 ; 0.68$ & & & & \\
\hline ICC & 0.89 & & & & \\
\hline \multicolumn{6}{|l|}{ Femur length } \\
\hline Intergrowth 21 & $1.21 \pm 0.92$ & & $1.34(0.63 ; 1.81)$ & & $-1.53 ; 4.00$ \\
\hline Salomon & $0.36 \pm 0.71$ & & $0.47(-0.07 ; 0.77)$ & & $-1.85 ; 2.57$ \\
\hline Difference & $0.85 \pm 0.21$ & $<0.001$ & $0.88(0.73 ; 0.97)$ & $<0.001$ & $0.21 ; 1.43$ \\
\hline LOA & $0.43 ; 1.27$ & & & & \\
\hline ICC & 0.63 & & & & \\
\hline
\end{tabular}

* Paired t test $p$ value

† Wilcoxon signed ranks test $p$ value

₹ Intraclass correlation calculation for abdominal circumference z scores excluded one participant with extreme values (9.9 using Intergrowth equations and 5.22 using Salomon equations)

LOA limits of agreement, ICC intraclass correlation coefficient

Table 4 Abnormal z scores using Intergrowth 21st or Salomon equations in the second trimester

\begin{tabular}{|c|c|c|c|c|}
\hline \multirow[t]{2}{*}{ Anthropometrics } & \multicolumn{4}{|c|}{ Abnormal z scores n (\%) } \\
\hline & $<2.5$ th centile & $<10$ th centile & $>$ 90th centile & $>$ 97.5th centile \\
\hline \multicolumn{5}{|l|}{ Biparietal diameter } \\
\hline Intergrowth 21 & $4(2.1)$ & $16(8.4)$ & $1(0.5)$ & $1(0.5)$ \\
\hline Salomon & $1(0.5)$ & $4(2.1)$ & $1(0.5)$ & $1(0.5)$ \\
\hline \multicolumn{5}{|c|}{ Abdominal circumference } \\
\hline Intergrowth 21 & $1(0.5)$ & $3(1.6)$ & $69(36.3)$ & $28(14.7)$ \\
\hline Salomon & $0(0)$ & $1(0.5)$ & $5(2.6)$ & $2(1.1)$ \\
\hline \multicolumn{5}{|l|}{ Head circumference } \\
\hline Intergrowth 21 & $0(0)$ & $1(0.5)$ & $49(25.8)$ & $15(7.9)$ \\
\hline Salomon & $0(0)$ & $0(0)$ & $34(17.9)$ & $3(1.6)$ \\
\hline \multicolumn{5}{|l|}{ Femur length } \\
\hline Intergrowth 21 & $0(0)$ & $2(1.1)$ & $103(54.2)$ & $32(16.8)$ \\
\hline Salomon & $0(0)$ & $4(2.1)$ & $13(6.8)$ & $2(1.1)$ \\
\hline
\end{tabular}


Table 5 Agreement and reliability of fetal biometrics z scores using Intergrowth 21st and Salomon equations in the third trimester

\begin{tabular}{|c|c|c|c|c|c|}
\hline Anthropometrics & Mean \pm SD & p-value ${ }^{*}$ & Median (IQR) & $p$-value ${ }^{\dagger}$ & Range \\
\hline \multicolumn{6}{|l|}{ Biparietal diameter } \\
\hline Intergrowth 21 & $-0.91 \pm 0.70$ & & $-0.89(-1.31 ;-0.44)$ & & $-2.62 ; 0.78$ \\
\hline Salomon & $-0.53 \pm 0.64$ & & $-0.49(-0.90 ;-0.11)$ & & $-2.10 ; 1.00$ \\
\hline Difference & $-0.39 \pm 0.07$ & $<0.001$ & $-0.38(-0.44 ;-0.34)$ & $<0.001$ & $-0.53 ;-0.22$ \\
\hline LOA & $-0.52 ;-0.25$ & & & & \\
\hline ICC & 0.85 & & & & \\
\hline \multicolumn{6}{|c|}{ Abdominal circumference } \\
\hline Intergrowth 21 & $0.81 \pm 0.71$ & & $0.75(0.29 ; 1.21)$ & & $-0.95 ; 2.89$ \\
\hline Salomon & $0.35 \pm 0.43$ & & $0.36(0.02 ; 0.63)$ & & $-0.68 ; 1.45$ \\
\hline Difference & $0.45 \pm 0.31$ & $<0.001$ & $0.37(0.25 ; 0.64)$ & $<0.001$ & $-0.27 ; 1.48$ \\
\hline LOA & $-0.16 ; 1.07$ & & & & \\
\hline ICC & 0.66 & & & & \\
\hline \multicolumn{6}{|l|}{ Head circumference } \\
\hline Intergrowth 21 & $0.76 \pm 0.70$ & & $0.70(0.39 ; 1.21)$ & & $-0.87 ; 2.49$ \\
\hline Salomon & $0.85 \pm 0.48$ & & $0.79(0.58 ; 1.17)$ & & $-0.28 ; 2.05$ \\
\hline Difference & $-0.09 \pm 0.22$ & $<0.001$ & $-0.09(-0.18 ; 0.07)$ & 0.001 & $-0.59 ; 0.44$ \\
\hline LOA & $-0.52 ; 0.35$ & & & & \\
\hline ICC & 0.92 & & & & \\
\hline \multicolumn{6}{|l|}{ Femur length } \\
\hline Intergrowth 21 & $1.09 \pm 1.15$ & & $1.15(0.53 ; 1.75)$ & & $-2.44 ; 3.55$ \\
\hline Salomon & $0.07 \pm 0.90$ & & $0.13(-0.38 ; 0.55)$ & & $-2.54 ; 2.02$ \\
\hline Difference & $1.02 \pm 0.26$ & $<0.001$ & $1.04(0.91 ; 1.16)$ & $<0.001$ & $0.10 ; 1.53$ \\
\hline LOA & $0.50 ; 1.53$ & & & & \\
\hline ICC & 0.65 & & & & \\
\hline
\end{tabular}

* Paired t test $p$ value

† Wilcoxon signed ranks test $p$ value

LOA limits of agreement, ICC intraclass correlation coefficient

Table 6 Abnormal z scores using Intergrowth 21st or Salomon equations in the third trimester

\begin{tabular}{|c|c|c|c|c|}
\hline \multirow[t]{2}{*}{ Anthropometrics } & \multicolumn{4}{|c|}{ Abnormal z scores n (\%) } \\
\hline & $<2.5$ th centile & $<10$ th centile & $>$ 90th centile & $>$ 97.5th centile \\
\hline \multicolumn{5}{|l|}{ Biparietal diameter } \\
\hline Intergrowth 21 & $6(7.0)$ & $23(26.7)$ & $0(0)$ & $0(0)$ \\
\hline Salomon & $2(2.3)$ & $10(11.6)$ & $0(0)$ & $0(0)$ \\
\hline \multicolumn{5}{|c|}{ Abdominal circumference } \\
\hline Intergrowth 21 & $0(0)$ & $0(0)$ & $17(19.8)$ & $5(5.8)$ \\
\hline Salomon & $0(0)$ & $0(0)$ & $3(3.5)$ & $0(0)$ \\
\hline \multicolumn{5}{|c|}{ Head circumference } \\
\hline Intergrowth 21 & $0(0)$ & $0(0)$ & $19(22.1)$ & $4(4.7)$ \\
\hline Salomon & $0(0)$ & $0(0)$ & $18(20.9)$ & $1(1.2)$ \\
\hline \multicolumn{5}{|l|}{ Femur length } \\
\hline Intergrowth 21 & $2(2.3)$ & $4(4.7)$ & $34(39.5)$ & $17(19.8)$ \\
\hline Salomon & $3(3.5)$ & $6(7.0)$ & $5(5.8)$ & $1(1.2)$ \\
\hline
\end{tabular}


smaller FL [35, 36] than older machines as in our study [31] and in Salomon's [16].

When AC was used as a proxy of fetal size estimation [2], the proportions of small fetuses were low for both charts which may indicate the difficulty ultrasonography has in identifying small fetuses [15, 37]. However, the proportions of both small and large fetuses were higher with Intergrowth 21st equations than with Salomon equations and a similar trend was remarked with $\mathrm{HC}$, suggesting the tendency of Intergrowth 21st equations to underestimate the size in small measurements and to overestimate it in high measurements [3, 34]. Thus, the choice of one or another of these references would implies very different medical interventions, follow-up, and resources allocation as well as stress put on patients $[4,27]$.

It is well documented that pregnancies affected by malaria, as in our study, are subject to fetal growth restriction [31, 38]. Thus, the number of small fetuses was expected to be high even if differences would be found between the charts. Surprisingly, this number was very low and the number of large fetuses was high. We suspect gestational age determination to be a possible cause of such situation. Indeed, pregnancies were dated late owing to the study design, [29] using a combination of fetal biometry measurements [33]. Late dating is less accurate than early dating. However, this is common practice in sub-Saharan Africa where almost three out of four pregnant women attend their first antenatal clinic during the second or third trimester, or not at all [39]. Although the combination of fetal anthropometric measurement is the recommended method at this stage of pregnancy, [40] it could produce redundant relationship when used for determining both gestational age and fetal size [4]. This is of particular concern in areas where malaria in pregnancy is common such as in Burkina Faso [41]. Gestational age could be underestimated in case of symmetric fetal growth restriction [33], hiding the adverse effect of malaria [42]. However, the difficulty for estimating the gestational age applies to both sets of equations when calculating $\mathrm{z}$ scores. Therefore, the differences between the charts are probably not due only to pregnancy dating problems, as shown by the positive and significant slopes in linear regressions. In addition, pregnant women included in this clinical trial, besides malaria, did not have any other chronic or major disease with adverse effect on fetal growth [29].

This is a post-hoc analysis and thus, has some limitations. Physicians performing the ultrasound scans are not professional sonographers even if trained ad hoc. In addition, the study design was not conceived to evaluate two different methods for the assessment of fetal biometry. Moreover, the use of European references equations may not be appropriate for African populations. Gestational age determined in late pregnancy is also another limitation because of less accuracy. Our study population prone to malaria was quite selected and this maybe introduce a bias. However, a recent study showed that the difference between the two charts remained while using fetal biometric measurements from pregnant women as healthy as those in the Intergrowth 21st study [43].

\section{Conclusion}

The agreement between Intergrowth 21st and Salomon equations, besides $\mathrm{HC}$, was poor. This would imply different clinical decisions regarding the management of the pregnancy and the delivery. Encouraging women to attend antenatal clinics earlier and to use preventive measures against malaria such as long-lasting insecticidal bed nets, would probably be much more beneficial than just dating gestation or determining fetal size.

\section{Supplementary information}

Supplementary information accompanies this paper at https://doi.org/10 1186/s12884-020-03183-5.

Additional file 1: Supplemental Table 1. Agreement and reliability of fetal biometrics z scores using Intergrowth 21 st and Salomon equations.

\begin{abstract}
Abbreviations
AC: Abdominal circumference; BPD: Biparietal diameter; FL: Femur length; HC: Head circumference; ICC: Intraclass correlation coefficient; INTERGROWTH - 21st: International fetal and newborn growth consortium for the twentyfirst century; LLIN: Long lasting insecticidal net; LOA: Limits of agreement; PREGACT: Safe and efficacious artemisinin-based combination treatments for African pregnant women with malaria
\end{abstract}

\section{Acknowledgements}

We thank the participants of the PREGACT study, the field team in Burkina Faso, and Université Catholique de Louvain in Belgium for the provision of a Ph. D grant.

\section{Authors' contributions}

UDA and JPV conceived the PREGACT trial. Data were collected by ZSH, TMC, VI and HT; RR supervised the conduct, monitoring and data management of the PREGACT trial; BB and RA suggested the idea of the paper. BB analyzed the data, and drafted the manuscript; All authors reviewed the manuscript and approved the version to be submitted.

\section{Funding}

The study received funds from- the European and Developing Countries Clinical Trials Partnership, the Malaria in Pregnancy granted by the Bill and Melinda Gates Foundation - USA through Liverpool School of Tropical Medecine - UK, the Netherlands-African Partnership for Capacity Development and Clinical Interventions Against Poverty-related diseases (NACCAP) -

Netherlands, the Directorate-General for Development Cooperation (DGDC) Belgium, and the Medical Research Council (MRC) - UK.

The funding institutions were not involved in designing the trial, and in collecting, analyzing, interpreting the data and in writing the manuscript.

\section{Availability of data and materials}

Data supporting the findings are not publicly available. Access could be granted upon motivated request to Tinto Halidou.

\section{Ethics approval and consent to participate}

The PREGACT study received approvals from- the Institutional Review Board of the Institute of Tropical Medicine, Antwerp, Belgium; the Ethics committee of the University Hospital, Antwerp, Belgium; the Institutional Ethics 
committee of Centre Muraz and the Ethics committee of the Ministry of Health, Burkina Faso.

All the participants provided a written informed consent form before being enrolled in the study. Datasets were anonymized.

\section{Consent for publication}

Not applicable.

\section{Competing interests}

No conflicts of interest.

\section{Author details}

${ }^{1}$ IRSS-Clinical Research Unit of Nanoro, Nanoro, Burkina Faso. ${ }^{2}$ Intitut de recherche expérimentale et clinique, Université catholique de Louvain, Brussels, Belgium. ${ }^{3}$ Public Health Department, Institute of Tropical Medicine, Antwerp, Belgium. ${ }^{4}$ Global Health Institute, University of Antwerp, Antwerp, Belgium. ${ }^{5}$ Medical Research Council Unit The Gambia at the London School of Hygiene and Tropical Medicine, London, UK.

\section{Received: 14 November 2019 Accepted: 17 August 2020}

\section{Published online: 26 August 2020}

\section{References}

1. O'Gorman N, Salomon LJ. Fetal biometry to assess the size and growth of the fetus. Best Pract Res Clin Obstet Gynaecol. 2018;49:3-15.

2. Mayer C, Joseph KS. Fetal growth: a review of terms, concepts and issues relevant to obstetrics. Ultrasound Obstet Gynecol. 2013;41(2):136-45.

3. Zhang J, Merialdi M, Platt LD, Kramer MS. Defining normal and abnormal fetal growth: promises and challenges. Am J Obstet Gynecol. 2010;202(6): 522-8.

4. Ioannou C, Talbot K, Ohuma E, Sarris I, Villar J, Conde-Agudelo A, et al. Systematic review of methodology used in ultrasound studies aimed at creating charts of fetal size. BJOG. 2012;119(12):1425-39.

5. American College of Obstetricians and Gynecologists. ACOG Practice Bulletin No. 204: fetal growth restriction. Obstet Gynecol. 2019;133(2):e97-e109.

6. McCarthy EA, Walker SP. International fetal growth standards: one size fits all. Lancet. 2014;384(9946):835-6.

7. Gardosi J. Intrauterine growth restriction: new standards for assessing adverse outcome. Best Pract Res Clin Obstet Gynaecol. 2009:23(6):741-9.

8. Sananes N, Guigue V, Kohler M, Bouffet N, Cancellier M, Hornecker F, et al. Use of Z-scores to select a fetal biometric reference curve. Ultrasound Obstet Gynecol. 2009:34(4):404-9.

9. Cheng YKY, Lu J, Leung TY, Chan YM, Sahota DS. Prospective assessment of INTERGROWTH-21(st) and World Health Organization estimated fetal weight reference curves. Ultrasound Obstet Gynecol. 2018;51(6):792-8.

10. Papageorghiou AT, Kennedy SH, Salomon LJ, Altman DG, Ohuma EO, Stones W, et al. The INTERGROWTH-21(st) fetal growth standards: toward the global integration of pregnancy and pediatric care. Am J Obstet Gynecol. 2018;218(2S):S630-40.

11. Hanson M, Kiserud T, Visser GHA, Brocklehurst $P$, Schneider EB. Optimal fetal growth: a misconception? Am J Obstet Gynecol. 2015;213(3):332 e331-332. e334.

12. Buck Louis GM, Grewal J, Albert PS, Sciscione A, Wing DA, Grobman WA et al. Racial/ethnic standards for fetal growth: the NICHD Fetal Growth Studies. Am J Obstet Gynecol. 2015;213(4):449 e441-449.e441.

13. Grantz KL, Hediger ML, Liu D, Buck Louis GM. Fetal growth standards: the NICHD fetal growth study approach in context with INTERGROWTH-21st and the World Health Organization multicentre growth reference study. Am J Obstet Gynecol. 2018;218(2S):S641-55 e628.

14. Kiserud T, Benachi A, Hecher K, Perez RG, Carvalho J, Piaggio G, et al. The World Health Organization fetal growth charts: concept, findings, interpretation, and application. Am J Obstet Gynecol. 2018;218(2S):S619-29.

15. Vayssière C, Sentilhes L, Ego A, Bernard C, Cambourieu D, Flamant C, et al Fetal growth restriction and intra-uterine growth restriction: guidelines for clinical practice from the French College of Gynaecologists and Obstetricians. Eur J Obstet Gynecol Reprod Biol. 2015:193:10-8.

16. Salomon LJ, Duyme M, Crequat J, Brodaty G, Talmant C, Fries N, et al. French fetal biometry: reference equations and comparison with other charts. Ultrasound Obstet Gynecol. 2006;28(2):193-8.
17. Kurmanavicius J, Wright EM, Royston P, Wisser J, Huch R, Huch A, et al. Fetal ultrasound biometry: 1. Head reference values. Br J Obstet Gynaecol. 1999; 106(2):126-35.

18. Kurmanavicius J, Wright EM, Royston P, Zimmermann R, Huch R, Huch A, et al. Fetal ultrasound biometry: 2. Abdomen and femur length reference values. Br J Obstet Gynaecol. 1999;106(2):136-43.

19. Chitty LS, Altman DG, Henderson A, Campbell S. Charts of fetal size: 2. Head measurements. Br J Obstet Gynaecol. 1994;101(1):35-43.

20. Chitty LS, Altman DG, Henderson A, Campbell S. Charts of fetal size: 3 Abdominal measurements. Br J Obstet Gynaecol. 1994;101(2):125-31.

21. Chitty LS, Altman DG, Henderson A, Campbell S. Charts of fetal size: 4 Femur length. Br J Obstet Gynaecol. 1994;101(2):132-5.

22. Leung TN, Pang MW, Daljit SS, Leung TY, Poon CF, Wong SM, et al. Fetal biometry in ethnic Chinese: biparietal diameter, head circumference, abdominal circumference and femur length. Ultrasound Obstet Gynecol. 2008:31(3):321-7.

23. Adiri CO, Anyanwu GE, Agwuna KK, Obikili EN, Ezugworie OJ, Agu AU, et al. Use of fetal biometry in the assessment of gestational age in south East Nigeria: femur length and biparietal diameter. Niger J Clin Pract. 2015;18(4): 477-82.

24. Munjanja SP, Masona D, Masvikeni S. Fetal biparietal diameter and head circumference measurements: results of a longitudinal study in Zimbabwe. Int J Gynaecol Obstet. 1988;26(2):223-8.

25. Muñoz WP, Moore PJ, MacKinnon A, Haines LM. Biparietal diameter and menstrual age in the black population attending edendale hospital. J Clin Ultrasound. 1986;14(9):681-8.

26. Aliyu Labaran D, Kurjak A, Wataganara T, de Sá Renato Augusto M, Pooh R, Sen C, et al. Ultrasound in Africa: what can really be done? J Perinat Med. 2016;44(2):119-23.

27. Papageorghiou AT, Ohuma EO, Altman DG, Todros T, Cheikh Ismail L, Lambert A, et al. International standards for fetal growth based on serial ultrasound measurements: the fetal growth longitudinal study of the INTE RGROWTH-21st project. Lancet. 2014;384(9946):869-79.

28. Collège français d'échographie foetale. Compte rendu du séminaire de travail du Collège français d'échographie fœtal (CFEF) sur les référentiels et standards de biométrie fœtale. Gynécol Obstét Fertil Sénol. 2017; 45(10):545-51.

29. Nambozi M, Mulenga M, Halidou T, Tagbor H, Mwapasa V, Phiri LK, et al. Safe and efficacious artemisinin-based combination treatments for African pregnant women with malaria: a multicentre randomized control trial. Reprod Health. 2015;12(5):5.

30. The PREGACT Study Group. Four Artemisinin-based treatments in African pregnant women with malaria. N Engl J Med. 2016;374(10):913-27.

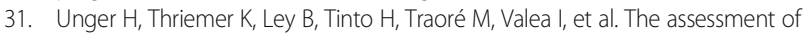
gestational age: a comparison of different methods from a malaria pregnancy cohort in sub-Saharan Africa. BMC Pregnancy Childbirth. 2019;19(1):12.

32. MiP. Ultrasound reference manual for pregnancy dating. Developed for the Assessing the Safety of Antimalarials during early Pregnancy (ASAP) Study through support from the Malaria in Pregnancy Consortium (MiPC). MiPC. 2012

33. Hadlock FP, Deter RL, Harrist RB, Park SK. Estimating fetal age: computerassisted analysis of multiple fetal growth parameters. Radiology. 1984;152(2): 497-501.

34. Stirnemann JJ, Fries N, Bessis R, Fontanges M, Mangione R, Salomon LJ. Implementing the INTERGROWTH-21(st) fetal growth standards in France: a 'flash study' of the college Francais d'Echographie Foetale (CFEF). Ultrasound Obstet Gynecol. 2017:49(4):487-92.

35. Okland I, Bjastad TG, Johansen TF, Gjessing HK, Grottum P, Eik-Nes SH. Narrowed beam width in newer ultrasound machines shortens measurements in the lateral direction: fetal measurement charts may be obsolete. Ultrasound Obstet Gynecol. 2011;38(1):82-7.

36. Morales-Rosello J, Hervas-Marin D, Stirrup O, Perales-Marin A, Khalil A. International standards for fetal growth: relevance of advances in ultrasound technology. Ultrasound Obstet Gynecol. 2015;46(5):631-2.

37. Monier I, Blondel B, Ego A, Kaminiski M, Goffinet F, Zeitlin J. Poor effectiveness of antenatal detection of fetal growth restriction and consequences for obstetric management and neonatal outcomes: a French national study. BJOG. 2015;122(4):518-27.

38. Huynh B-T, Ghafari C, Saal J, Cot M, Fievet N, Deloron P, et al. Fetal growth restriction is associated with malaria in pregnancy: a prospective longitudinal study in Benin. J Infect Dis. 2016;214(3):417-25. 
39. Moller A-B, Petzold M, Chou D, Say L. Early antenatal care visit: a systematic analysis of regional and global levels and trends of coverage from 1990 to 2013. Lancet Glob Health. 2017;5(10):e977-83.

40. Papageorghiou AT, Kemp B, Stones W, Ohuma EO, Kennedy SH, Purwar M, et al. Ultrasound-based gestational-age estimation in late pregnancy. Ultrasound Obstet Gynecol. 2016;48(6):719-26.

41. McKittrick ND, Malhotra IJ, Vu DM, Boothroyd DB, Lee J, Krystosik AR, et al. Parasitic infections during pregnancy need not affect infant antibody responses to early vaccination against Streptococcus pneumoniae, diphtheria, or Haemophilus influenzae type B. PLoS Negl Trop Dis. 2019; 13(2):-e0007172.

42. Rijken MJ, Papageorghiou AT, Thiptharakun S, Kiricharoen S, Dwell SL, Wiladphaingern J, et al. Ultrasound evidence of early fetal growth restriction after maternal malaria infection. PLoS One. 2012;7(2):e31411.

43. Heude B, Le Guern M, Forhan A, Scherdel P, Kadawathagedara M, Dufourg $\mathrm{M}-\mathrm{N}$, et al. Are selection criteria for healthy pregnancies responsible for the gap between fetal growth in the French national Elfe birth cohort and the Intergrowth-21st fetal growth standards? Paediatr Perinat Epidemiol. 2019; 33(1):47-56.

\section{Publisher's Note}

Springer Nature remains neutral with regard to jurisdictional claims in published maps and institutional affiliations.

Ready to submit your research? Choose BMC and benefit from:

- fast, convenient online submission

- thorough peer review by experienced researchers in your field

- rapid publication on acceptance

- support for research data, including large and complex data types

- gold Open Access which fosters wider collaboration and increased citations

- maximum visibility for your research: over $100 \mathrm{M}$ website views per year

At BMC, research is always in progress.

Learn more biomedcentral.com/submissions 